\title{
Effect of different doses and time-courses of corticosteroid treatment in patients with acute respiratory distress syndrome: A meta-analysis
}

\author{
SHUANGSHUANG SUN ${ }^{1,2}$, DADONG LIU ${ }^{2}$, HAO ZHANG $^{3}$, XIUWEI ZHANG ${ }^{1}$ and BING WAN ${ }^{1}$ \\ ${ }^{1}$ Department of Respiratory and Critical Care Medicine, The Affiliated Jiangning Hospital of Nanjing Medical University, \\ Nanjing, Jiangsu 210002; ${ }^{2}$ ICU and ${ }^{3}$ Emergency Department, The Affiliated Hospital of Jiangsu University, \\ Zhenjiang, Jiangsu 212001, P.R. China
}

Received February 14, 2019; Accepted September 26, 2019

DOI: $10.3892 /$ etm.2019.8167

\begin{abstract}
While previous trials have indicated that the use of corticosteroids for patients with acute respiratory distress syndrome (ARDS) is effective, the dosage and time-course for the use of corticosteroids remain a subject of controversy. The present study aimed to address and resolve these problems. PubMed, Embase and the Cochrane Library databases were searched from inception to March 2017 for randomized controlled trials (RCTs), which included patients with ARDS using corticosteroids. Related data were extracted independently by two investigators. The Mantel-Haenszel method was used with random-effects modeling to calculate the pooled odds ratio (OR) and $95 \%$ confidence interval (CI) for the mortality of patients with ARDS, and the risk of new infection arising from the use of glucocorticoids. The inverse variance method was used to calculate the mean difference (MD) and 95\% CI for the duration of mechanical-free ventilation and the ratio of arterial oxygen partial pressure to fractional inspired oxygen $\left(\mathrm{PaO}_{2} / \mathrm{FIO}_{2}\right.$ ratio). The use of low-dose corticosteroids significantly reduced the mortality rate of patients with ARDS (OR: 0.43; 95\% CI: 0.24-0.79; $\mathrm{P}=0.006)$ while the use of high-dose corticosteroids provided no significant benefit to reducing the mortality rate (OR: 1.33; 95\% CI: 0.86-2.04; $\mathrm{P}=0.20$ ). The present study identified that glucocorticoids reduced the mortality rate of patients during the early stages of ARDS (OR: $0.61 ; 95 \% \mathrm{CI}$ :
\end{abstract}

Correspondence to: Dr Bing Wan, Department of Respiratory and Critical Care Medicine, The Affiliated Jiangning Hospital of Nanjing Medical University, 169 Hushan Road, Nanjing, Jiangsu 210002, P.R. China

E-mail: bingwan76@163.com

Abbreviations: ARDS, acute respiratory distress syndrome; RCT, randomized controlled trial; $\mathrm{OR}$, odds ratio; $\mathrm{CI}$, confidence interval; MD, mean difference; M-H, Mantel-Haenszel

Key words: corticosteroid, ARDS, dose, time-course, meta-analysis
0.43-0.86; $\mathrm{P}=0.005)$. Glucocorticoids significantly reduced the duration of mechanical ventilation (MD: 3.08 ; $95 \% \mathrm{CI}$ : 1.49-4.68; $\mathrm{P}<0.05)$ and significantly improved the $\mathrm{PaO}_{2} / \mathrm{FiO}_{2}$ ratio (MD: 66.39; 95\% CI: 57.79-74.98; $\mathrm{P}<0.05$ ). The use of corticosteroids did not significantly increase the rate of infectious complications (OR: 0.60; 95\% CI: 0.32-1.12; P>0.05). The use of low-dose corticosteroids may significantly reduce the mortality rate, particularly in the early stages of ARD, shorten the duration of mechanical ventilation and improve the $\mathrm{PaO}_{2} / \mathrm{FiO}_{2}$ ratio without increasing the risk of a new infection.

\section{Introduction}

Acute respiratory distress syndrome (ARDS) is a life-threatening disease with high mortality rates of 40-50\% (1), and can lead to hypoxemic respiratory failure requiring mechanical ventilation $(2,3)$. There are many causes for this syndrome, including shock, aspiration pneumonia, infection, sepsis and a combination of other reasons (1). This condition can give rise to excessive and persistent inflammation by increasing vascular permeability, extravasation of plasma and leucocyte infiltration (2), resulting in a series of complications, such as sepsis, acute pancreatitis, pulmonary fibrosis and disseminated intravascular coagulation. These diseases can lead to secondary systemic inflammatory reactions that result in multiple organ failure, such as respiratory, circulatory and renal failure (4). If there were no effective and timely treatments, this disease would exacerbate quickly and even become life-threatening within just a short period of time.

Glucocorticoids have been reported as important substances in maintaining endothelial integrity and vascular permeability (5-8). Glucocorticoids also modulate many pro-inflammatory and anti-inflammatory cytokines, and play a key role in immune homeostasis (9). Consequently, corticosteroids are considered to represent an effective therapy for patients with ARDS. Previous randomized trials and some meta-analyses (10-13) have demonstrated the efficacy of corticosteroids in reducing the mortality of ARDS.

However, several important issues remain unresolved and are under dispute. First and foremost, it is not clear as to what 
dose and time-course of corticosteroids can reduce mortality in patients with ARDS. Previously published meta-analyses were limited because they illustrated the problem from just one or a few perspectives (12-14), such as the dose of glucocorticoid. Secondly, glucocorticoids have many side effects, including an increase in infectious and neuromyopathic complications. Additional potential risks include hyperglycemia, poor wound healing, psychosis, pancreatitis and prolonged muscle weakness with impaired functional status $(15,16)$.

Furthermore, it is difficult to control the side effects of glucocorticoid while achieving an effective therapeutic effect. Previous meta-analyses have not fully addressed the issues relating to complications $(17,18)$. Previous trials showed that methylprednisolone could improve the ratio of arterial oxygen partial pressure to fractional inspired oxygen $\left(\mathrm{PaO}_{2} / \mathrm{FIO}_{2}\right.$ ratio $)$ and reduce periods of mechanical ventilation in ARDS $(10,12)$. Furthermore, the impact of dose or treatment duration on the efficacy of corticosteroids remains unclear. The present study conducted a systematic review and quantitative synthesis to address these issues.

\section{Materials and methods}

Search strategy. A systematic search into the PubMed (http://www.ncbi.nlm.nih.gov/pubmed/), Embase (EMBASE.com) and Cochrane Library databases (www. update-software.com/clibng/cliblogon.htm) was conducted, from inception to May 2017, restricting the publication language to English. The following key words were used as search terms: 'ARDS'; 'adult respiratory distress syndrome'; 'acute respiratory distress syndrome'; 'respiratory insufficiency'; 'shock lung'; 'respiratory failure'; 'lung injury' AND 'steroids'; 'corticosteroids'; 'glucocorticoids'; 'hydrocortisone'; 'prednisolone' AND 'randomized controlled clinical trials'; 'controlled trials'; and 'randomized trials' and 'random control test'.

Inclusion and exclusion criteria. The present study included all randomized controlled trial (RCT) designs that reported mortality outcomes, users of different doses of corticosteroid along with non-users for comparison, and the users of corticosteroid in different phases of ARDS.

The diagnosis criterion of ARDS was in accordance with the current Berlin Definition of Acute Respiratory Distress Syndrome (19). In order to increase the reliability of data and experiments, all patients with ARDS were included, depending upon the standard of the relative trial period.

In order to assess the efficiency of corticosteroids on ARDS, data relating to the length of mechanical ventilation, the length of intensive care unit stay and the $\mathrm{PaO}_{2} / \mathrm{FIO}_{2}$ ratio were included. All patients were required to have a diagnosis of ARDS/acute lung injury and be 18 years of age, or older.

Previous studies were excluded if they were duplicated studies, did not use a control group, involved animal experiments, in vitro studies or multiple subjects, or if the identified study was a meeting abstract.

Quality assessment and data extraction. Data were extracted independently by two reviewers and any differences were resolved through discussion. Quality assessment

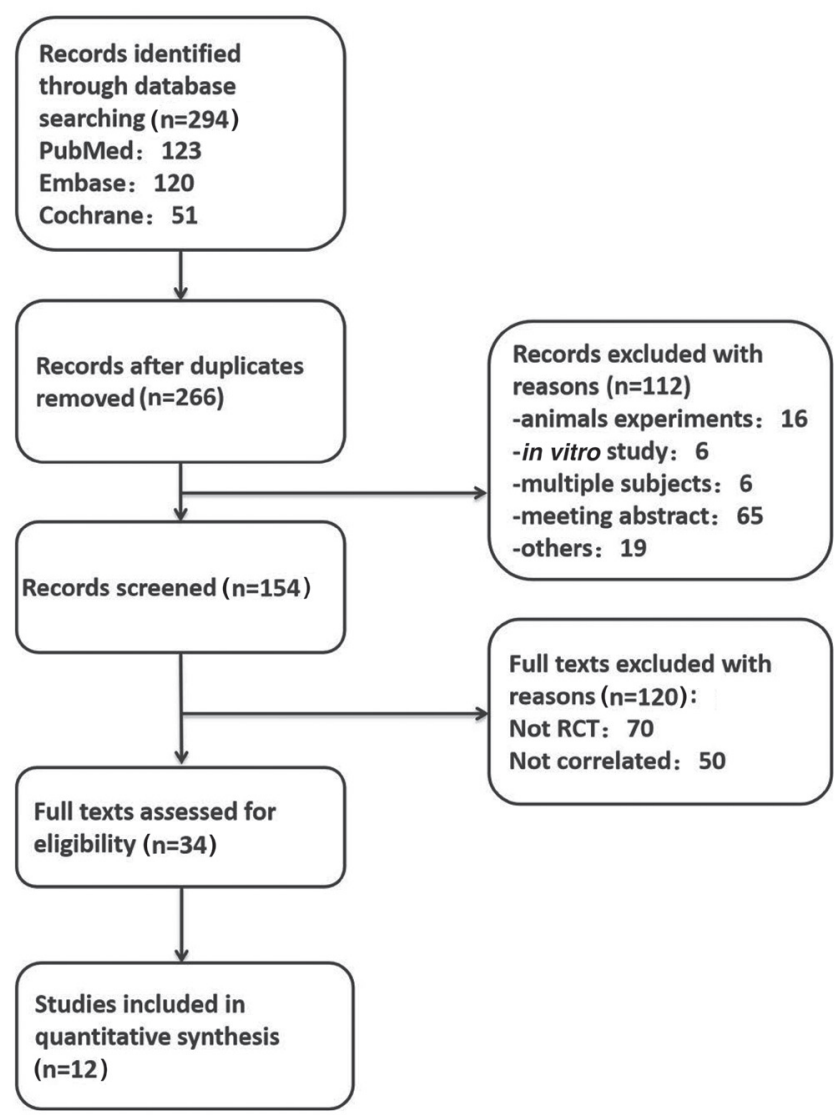

Figure 1. Literature screening procedure. RCT, randomized controlled trial.

of the previous studies was performed using The Cochrane Collaboration's Risk of Bias tool (20), reporting of randomization method, allocation concealment, blinding of outcome assessment, completeness of follow-up and bias of selective reporting. Review Manager 5.2 software (version 5.2; The Nordic Cochrane Centre, The Cochrane Collaboration; ims. cochrane.org/revman) was also used to create funnel plots with which to evaluate publication bias.

Statistical analysis. All data were assimilated using Review Manager 5.2 software provided by The Cochrane Collaboration Group. For dichotomous data, the Mantel-Haenszel (M-H) method was used to estimate the odds ratio (OR) with a $95 \%$ confidence interval (CI) (21). The mortality rate by the usage of low-dose and high-dose of corticosteroids, and mortality outcomes in patients with ARDS who were administered with steroids at different course using the $\mathrm{M}-\mathrm{H}$ method were compared. The mean difference (MD) was calculated between treatment and control groups for continuous outcomes, such as the duration of mechanical ventilation, the length of intensive care unit stay and $\mathrm{PaO}_{2} / \mathrm{FIO}_{2}$ ratios. The number of patients required for treatment was calculated as the inverse of the absolute risk reduction, based upon the pooled risk ratio and the baseline risk (20). $\mathrm{P}<0.05$ was considered to indicate a statistically significant difference. The $\mathrm{I}^{2}$ test was used to evaluate the pooled variation between all eligible trials and Cochran's Q statistic to assess heterogeneity. In addition, bias risk was also assessed, based upon standards reported in the Cochrane Handbook (22). 
Table I. Detailed features of the included studies.

\begin{tabular}{|c|c|c|c|c|c|c|c|}
\hline \multirow[b]{2}{*}{ Author, year } & \multicolumn{2}{|c|}{ Participants, n } & \multirow{2}{*}{$\begin{array}{c}\text { Clinical } \\
\text { trials }\end{array}$} & \multirow{2}{*}{$\begin{array}{l}\text { Phases of } \\
\text { clinical trials }\end{array}$} & \multirow{2}{*}{$\begin{array}{l}\text { Treatment } \\
\text { phase }\end{array}$} & \multirow[b]{2}{*}{ Regimen } & \multirow[b]{2}{*}{ (Refs. } \\
\hline & Treatment & Control & & & & & \\
\hline Annane et al, 2006 & 85 & 92 & Yes & IV & Early phase & $\begin{array}{l}\text { Hydrocortisone, } \\
200 \mathrm{mg} / \text { day for } 7 \text { days, } \\
\text { low dose }\end{array}$ & (10) \\
\hline Confalonieri et al, 2005 & 23 & 23 & Yes & IV & Early phase & $\begin{array}{l}\text { Hydrocortisone, } \\
240 \mathrm{mg} / \text { day for } 7 \text { days, } \\
\text { low dose }\end{array}$ & (11) \\
\hline Lee et al, 2005 & 12 & 8 & No & & Early phase & $\begin{array}{l}\text { Methylprednisolone } \\
2 \mathrm{mg} / \mathrm{kg} / \text { day for } 25 \text { days, } \\
\text { low dose }\end{array}$ & (24) \\
\hline Liu et al, 2012 & 12 & 14 & No & & Early phase & $\begin{array}{l}\text { Hydrocortisone, } \\
300 \mathrm{mg} / \text { day for } 7 \text { days, } \\
\text { low dose }\end{array}$ & (25) \\
\hline Meduri et al, 2007 & 63 & 28 & No & & $\begin{array}{l}\text { Early and } \\
\text { late phase }\end{array}$ & $\begin{array}{l}\text { Methylprednisolone, } \\
1 \mathrm{mg} / \mathrm{kg} / \text { day for } \\
28 \text { days, low dose }\end{array}$ & (12) \\
\hline Seam et al, 2012 & 55 & 24 & No & & Early phase & $\begin{array}{l}\text { Methylprednisolone, } \\
\text { low dose not available }\end{array}$ & (26) \\
\hline Steinberg et al, 2006 & 89 & 91 & Yes & IV & $\begin{array}{l}\text { Early and } \\
\text { late phase }\end{array}$ & $\begin{array}{l}\text { Methylprednisolone, } \\
2 \mathrm{mg} / \mathrm{kg} / \text { day for } 25 \text { days, } \\
\text { low dose }\end{array}$ & (27) \\
\hline Wan et al, 2011 & 38 & 43 & Yes & IV & Early phase & $\begin{array}{l}\text { Dexamethasone, } \\
1 \mathrm{mg} / \mathrm{kg} / \text { day for } \\
3 \text { days, low dose }\end{array}$ & (28) \\
\hline Foster, 2010 & 39 & 42 & No & & Not reported & $\begin{array}{l}\text { Methylprednisolone, } \\
3 \mathrm{mg} / \mathrm{kg} / \text { day for } \\
3 \text { days, high dose }\end{array}$ & (13) \\
\hline $\begin{array}{l}\text { Meduri and Eltorky } \\
2015\end{array}$ & 67 & 49 & No & & Not reported & $\begin{array}{l}\text { Glucocorticoid, } \\
3 \mathrm{mg} / \mathrm{kg} / \text { day for } \\
3 \text { days, high dose }\end{array}$ & (3) \\
\hline Weigelt et al, 1985 & 39 & 42 & No & & Early phase & $\begin{array}{l}\text { Methylprednisolone, } \\
120 \mathrm{mg} / \mathrm{kg} / \text { day for } \\
2 \text { days, high dose }\end{array}$ & (17) \\
\hline Bernard et al, 1987 & 50 & 49 & No & & Early phase & $\begin{array}{l}\text { Methylprednisolone, } \\
120 \mathrm{mg} / \mathrm{kg} / \text { day for } \\
1 \text { day, high dose }\end{array}$ & $(29)$ \\
\hline
\end{tabular}

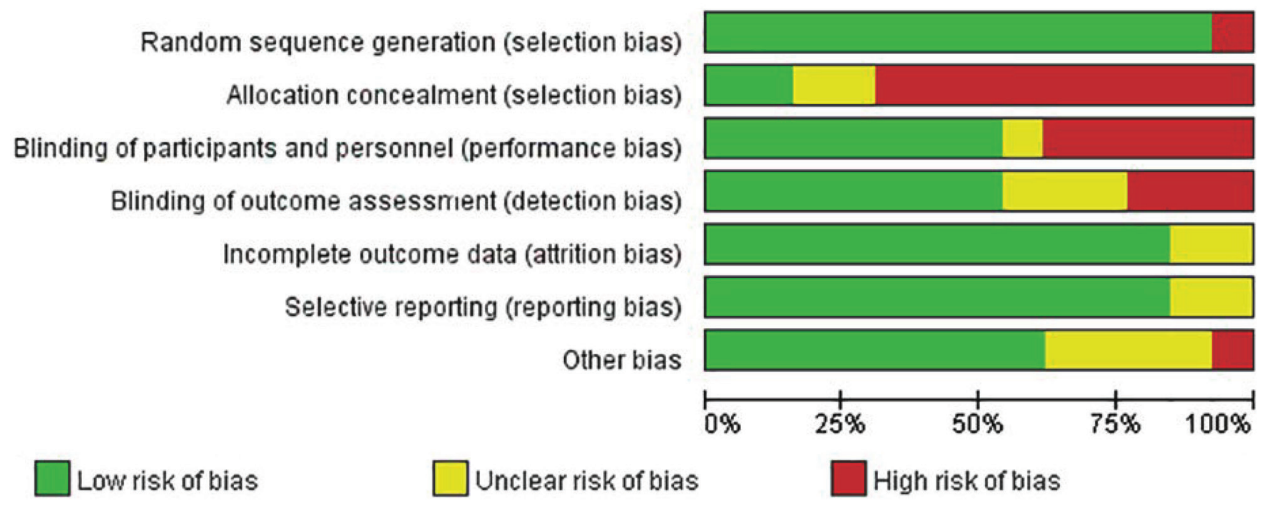

Figure 2. Quality assessment of studies. 


\section{Results}

Literature search results and population characteristics. Using the aforementioned methods, 294 published articles were identified, which were relevant to the topic of ARDS and glucocorticoids. A total of 28 duplicates and 112 other articles (animal experiments, in vitro studies, multiple subjects and wrong abstracts) were excluded, leaving 154 articles. Next, 120 more citations were excluded after careful review of the titles and abstracts. According to the specific inclusion and exclusion criteria of the present study, a total of 12 articles were eligible for the final meta-analysis. A flowchart of the present meta-analysis is presented in Fig. 1.

A total of 1,505 patients with ARDS were included, with 780 cases in the treatment group and 725 cases in the control group. The treatment group was divided into two groups depending on the dose and time-course.

In total, 8 trials used low-dose therapy and 4 trials used high-dose therapy (Table I). To keep consistency, the same cutoff value was used, and a dose of corticosteroid ( $\leq 2.0 \mathrm{mg} / \mathrm{kg} / \mathrm{day}$ or equivalent) of methylprednisolone or equivalent) was defined as low dose, while a dose of corticosteroids ( $>2.0 \mathrm{mg} / \mathrm{kg} / \mathrm{day}$ methylprednisolone or equivalent) was defined as a high dose, according to the guidelines for clinical usage of glucocorticoids (23).

The treatment group was divided into 2 groups depending on the specific phase of ARDS (Table I); there were 8 trials involving glucocorticoid intervention during the early phase of ARDS onset (course of disease $\leq 7$ days) and 2 trials involving the treatment of late ARDS with glucocorticoid (course of disease $>7$ days); other trials were excluded because of a lack of reporting. Standard care, mechanical ventilation and other supportive care were applied to patients in both groups.

Quality assessment. As presented in Fig. 2, the quality of the studies included in the present investigation was assessed using the Cochrane Risk of Bias Tool. Some studies failed to provide a clear method of blinding (including the blinding of participants, and personnel and outcome assessment), while a few studies revealed limitations in sample size. A funnel plot of publication bias is presented in Fig. 3; the plot is symmetrical and distributed at the top of the scale, thus indicating that there is either no publication bias or only minor publication bias.

Mortality outcomes in patients with ARDS who were treated with different doses of steroids. In total, 12 trials $(10-13,17,24-30)$ were deemed to be suitable to assess whether glucocorticoid treatment was beneficial to patients with ARDS in terms of reducing mortality. Sub-group analyses of the mortality data, according to different doses and duration of glucocorticoid therapy, were also performed. As shown in Fig. 4, 8 trials (10-12,24-28) were identified comparing the impact of low-dose glucocorticoid treatment on the mortality rates of patients with ARDS with appropriate controls. A significantly lower mortality was identified in the low-dose group compared with the controls (combined OR: 0.43; 95\% CI: 0.24-0.79; P<0.05). Another sub-group with only 4 trials identified $(13,17,29,30)$ studied

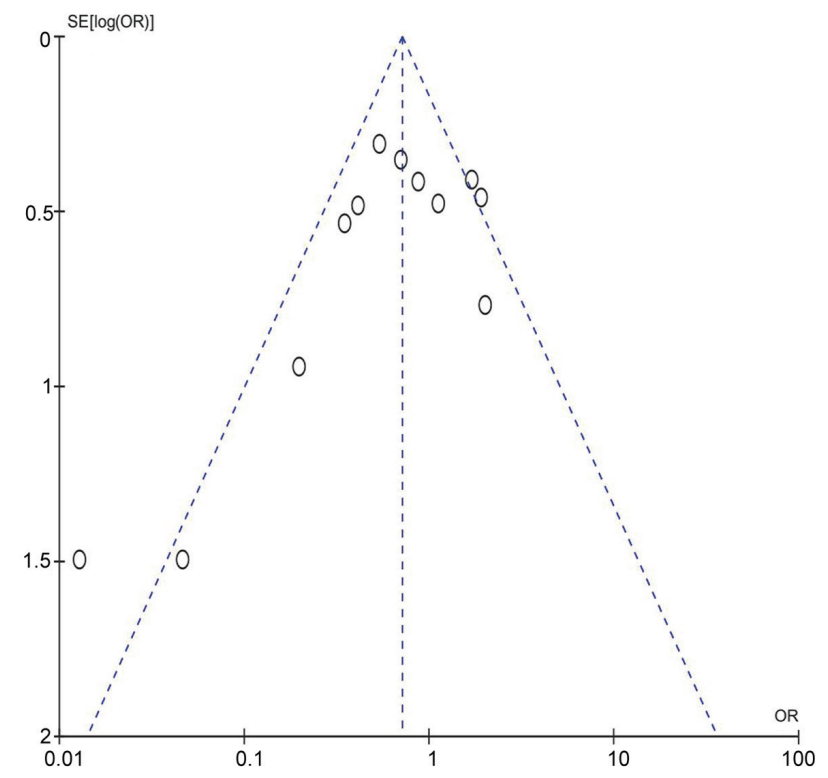

Figure 3. Funnel plots were created to evaluate publication bias using Review Manager 5.2 software (The Cochrane Collaboration). The plot appears symmetrical and distributed at the top of the scale, thus indicating that there is either no publication bias or only minor publication bias. OR, odds ratio.

the effect of high-dose glucocorticoid treatment on the mortality rates of ARDS. As shown in Fig. 4, the group of patients with ARDS receiving high-dose glucocorticoid treatment failed to show any benefit (combined OR: 1.33; 95\% CI: 0.86-2.04; P>0.05).

Mortality outcomes in patients with ARDS who were administered steroids at different times. As shown in Fig. 5, 8 trials $(10,11,17,24-26,28,29)$ were identified which compared the impact of early glucocorticoid administration on the mortality rates of patients with ARDS with the controls. Patients who were given corticosteroids early, compared with no corticosteroids, showed lower levels of mortality (OR: 0.61; 95\% CI: $0.43-0.86 ; \mathrm{P}=0.005)$. This analysis failed to show any benefit of late administration of corticosteroids compared with controls (no corticosteroids), in terms of mortality in patients with late ARDS $(\mathrm{P}>0.05)$.

Effect of steroid treatment on the duration of mechanical ventilation. A total of 4 trials $(10,12,27,28)$ were identified which investigated whether steroids could reduce the number of days on which patients with ARDS were mechanically ventilated. As shown in Fig. 6, the number of mechanical ventilation-free days was significantly higher in the treatment group compared with the control group (MD: 3.08; 95\% CI: 1.49-4.68; $\mathrm{P}<0.05)$.

Effect of steroid treatment on the $\mathrm{PaO}_{2} / \mathrm{FiO}_{2}$ ratio. A total of 3 trials $(11,12,28)$ were identified as having investigated whether corticosteroids could augment the $\mathrm{PaO}_{2} / \mathrm{FiO}_{2}$ ratio in patients with ARDS. As shown in Fig. 7, the $\mathrm{PaO}_{2} / \mathrm{FiO}_{2}$ ratio was significantly increased in the treatment group when compared with the controls (MD: 66.39; 95\% CI: 57.79-74.98; $\mathrm{P}<0.05)$. 


\begin{tabular}{|c|c|c|c|c|c|c|c|c|c|}
\hline \multirow[b]{2}{*}{ Studv or Subgroup } & \multicolumn{2}{|c|}{ Experimental } & \multicolumn{2}{|c|}{ Control } & \multirow{2}{*}{\multicolumn{2}{|c|}{$\begin{array}{c}\text { Odds Ratio } \\
\text { Weight } \quad \text { M-H, Random, } 95 \% \text { Cl }\end{array}$}} & \multirow{2}{*}{\multicolumn{3}{|c|}{$\begin{array}{l}\text { Odds Ratio } \\
\text { M-H, Random, } 95 \% \mathrm{Cl}\end{array}$}} \\
\hline & Events & Total & Events & Total & & & & & \\
\hline \multicolumn{10}{|l|}{ 1.2.1 low dose } \\
\hline Annane 2006 & 45 & 85 & 62 & 92 & $12.5 \%$ & $0.54[0.30,1.00]$ & & & \\
\hline Confalonieri 2005 & 0 & 23 & 7 & 23 & $2.3 \%$ & $0.05[0.00,0.88]$ & & & \\
\hline Lee 2005 & 1 & 12 & 7 & 8 & $2.3 \%$ & $0.01[0.00,0.24]$ & & & \\
\hline Liu 2012 & 2 & 12 & 7 & 14 & $4.7 \%$ & $0.20[0.03,1.27]$ & & & \\
\hline Meduri 2007 & 15 & 63 & 12 & 28 & $9.7 \%$ & $0.42[0.16,1.07]$ & & & \\
\hline Seam 2012 & 11 & 55 & 10 & 24 & $9.0 \%$ & $0.35[0.12,1.00]$ & & & \\
\hline Steinberg 2006 & 18 & 89 & 24 & 91 & $11.8 \%$ & $0.71[0.35,1.42]$ & & & \\
\hline Wan 2011 & 5 & 38 & 3 & 43 & $6.2 \%$ & $2.02[0.45,9.09]$ & & & \\
\hline Subtotal $(95 \% \mathrm{Cl})$ & & 377 & & 323 & $58.4 \%$ & $0.43[0.24,0.79]$ & & & \\
\hline Total events & 97 & & 132 & & & & & & \\
\hline \multirow{2}{*}{\multicolumn{10}{|c|}{$\begin{array}{l}\text { Heterogeneity: } \text { Tau }^{2}=0.33 ; \mathrm{Chi}^{2}=14.47, \mathrm{df}=7(\mathrm{P}=0.04) ; \mathrm{I}^{2}=52 \% \\
\text { Test for owerall effect: } Z=2.73(\mathrm{P}=0.006)\end{array}$}} \\
\hline & & & & & & & & & \\
\hline \multicolumn{10}{|l|}{ 1.2.2 high dose } \\
\hline Bernard 1987 & 30 & 50 & 31 & 49 & $10.8 \%$ & $0.87[0.39,1.96]$ & & & \\
\hline Foster 2010 & 13 & 39 & 13 & 42 & $9.8 \%$ & $1.12[0.44,2.84]$ & & & \\
\hline Gu 2003 & 50 & 67 & 31 & 49 & $10.9 \%$ & $1.71[0.77,3.80]$ & & & \\
\hline Weigelt 1985 & 18 & 39 & 13 & 42 & $10.0 \%$ & $1.91[0.77,4.74]$ & & & \\
\hline Subtotal (95\% Cl) & & 195 & & 182 & $41.6 \%$ & $1.33[0.86,2.04]$ & & & \\
\hline Total events & 111 & & 88 & & & & & & \\
\hline \multirow{2}{*}{\multicolumn{10}{|c|}{$\begin{array}{l}\text { Heterogeneity: } \operatorname{Tau}^{z}=0.00 ; \mathrm{Chi}^{2}=2.17, \mathrm{df}=3(\mathrm{P}=0.54) ; \mathrm{I}^{2}=0 \% \\
\text { Test for owerall effect: } Z=1.29(\mathrm{P}=0.20)\end{array}$}} \\
\hline & & & & & & & & & \\
\hline Total $(95 \% \mathrm{Cl})$ & & 572 & & 505 & $100.0 \%$ & $0.68[0.42,1.11]$ & & & \\
\hline Total events & 208 & & 220 & & & & & & \\
\hline \multicolumn{7}{|c|}{$\begin{array}{l}\text { Heterogeneity: } \text { Tau }^{2}=0.39 ; \mathrm{Chi}^{2}=28.16, \mathrm{df}=11(\mathrm{P}=0.003) ; \mathrm{I}^{2}=61 \% \\
\text { Test for owerall effect: } Z=1.55(\mathrm{P}=0.12)\end{array}$} & & & 10 \\
\hline \multicolumn{10}{|c|}{$\begin{array}{l}\text { Test for owerall effect: } Z=1.55(\mathrm{P}=0.12) \\
\text { Test for subarous differences: } \mathrm{Ch} \mathrm{i}^{2}=8.84 . \mathrm{df}=1(\mathrm{P}=0.003) . \mathrm{I}^{2}=88.7 \% \quad \text { Favours [experimental] Favours [control] }\end{array}$} \\
\hline
\end{tabular}

Figure 4. Meta-analysis of the mortality in patients with acute respiratory distress syndrome treated with low-dose and high-dose of corticosteroids. M-H, Mantel-Haenszel; CI, confidence interval.

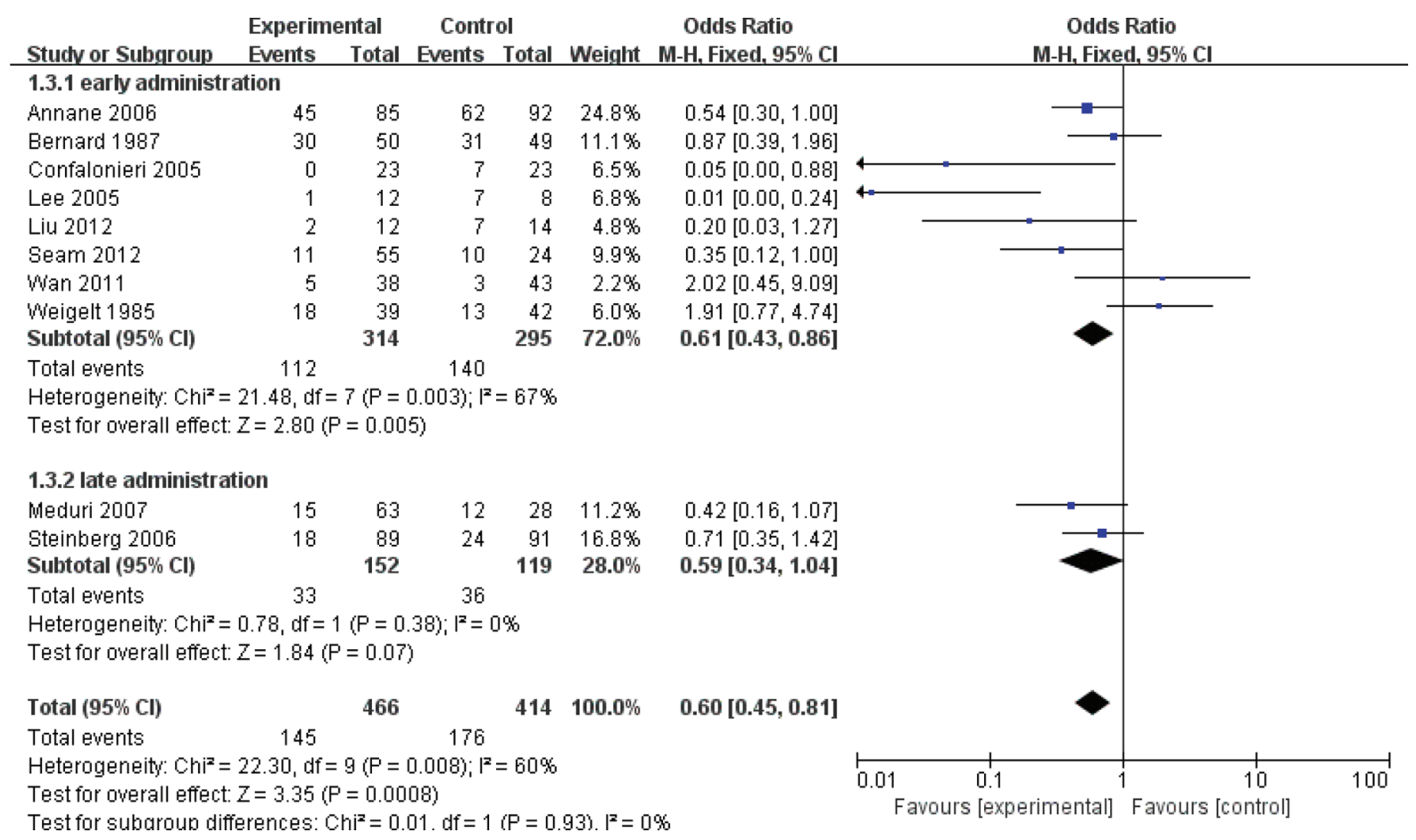

Figure 5. Mortality in patients with acute respiratory distress syndrome with different administration of steroids. M-H, Mantel-Haenszel; CI, confidence interval.

Meta-analysis of the risk of new infection in patients with ARDS treated with steroids. In total, 5 trials $(10-12,25,27)$ were identified which investigated whether corticosteroids could increase the risk of a new infection (side effects). As shown in Fig. 8, the use of corticosteroids did not increase the risk of a new infection when compared with controls (OR: 0.60; 95\% CI: 0.32-1.12; P>0.05). 


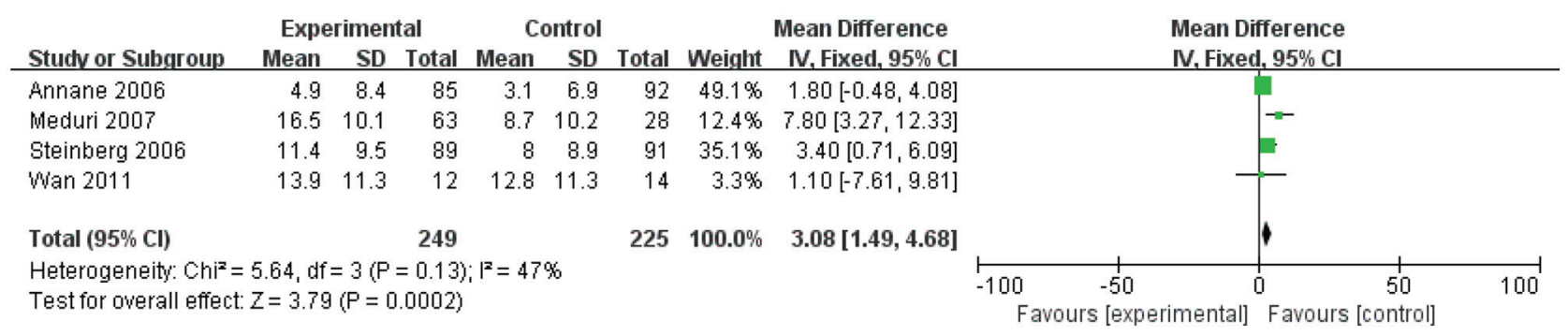

Figure 6. Meta-analysis of the effects of steroids on the duration of mechanical ventilation days. M-H, Mantel-Haenszel; CI, confidence interval.

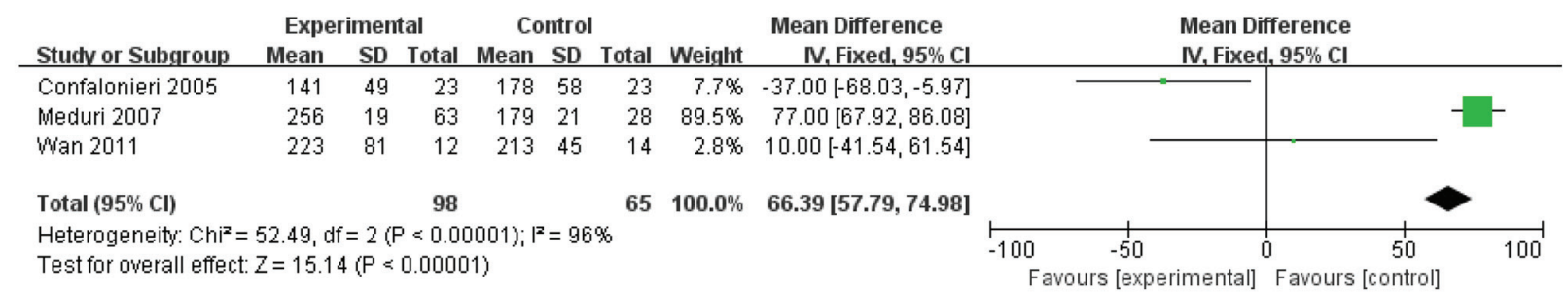

Figure 7. Meta-analysis of the effects of steroids on improving the ratio of arterial oxygen partial pressure to fractional inspired oxygen. CI, confidence interval.

\begin{tabular}{|c|c|c|c|c|c|}
\hline \multirow[b]{2}{*}{ Studv or Subgroup } & \multicolumn{2}{|c|}{ Experimental } & \multicolumn{2}{|c|}{ Control } & \multirow[b]{2}{*}{ Weight } \\
\hline & & Total & Events & Total & \\
\hline Annane 2006 & 12 & 85 & 12 & 92 & $27.6 \%$ \\
\hline Confalonieri 2005 & 0 & 23 & 4 & 23 & $4.1 \%$ \\
\hline Liu 2012 & 2 & 12 & 1 & 14 & $5.5 \%$ \\
\hline Meduri 2007 & 27 & 63 & 16 & 28 & $26.3 \%$ \\
\hline Steinberg 2006 & 23 & 89 & 43 & 91 & $36.4 \%$ \\
\hline Total $(95 \% \mathrm{Cl})$ & & 272 & & 248 & $100.0 \%$ \\
\hline Total events & 64 & & 76 & & \\
\hline
\end{tabular}

Odds Ratio Odds Ratio

H. Random, 95\% Cl

$1.10[0.46,2.59]$

$0.09[0.00,1.82]$

$2.60[0.21,32.90]$

$0.56[0.23,1.38]$

$0.39[0.21,0.73]$

$0.60[0.32,1.12]$

Test for overall effect: $Z=1.61(P=0.11)$

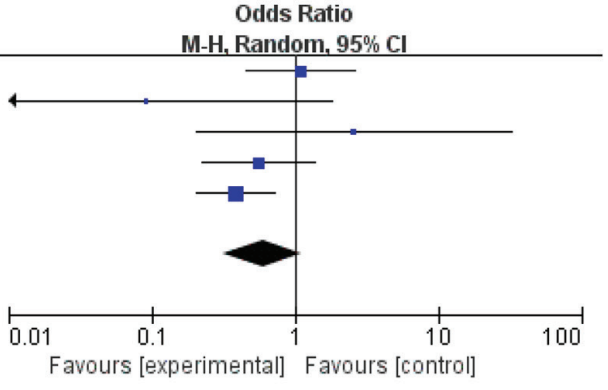

Figure 8. Meta-analysis of the risk of new infection of steroid treatment for patients with acute respiratory distress syndrome. M-H, Mantel-Haenszel; CI, confidence interval.

\section{Discussion}

ARDS is an inflammatory disease process of the lungs which occurs in response to a variety of reasons. ARDS is characterized clinically by severe hypoxemia, reduced lung compliance and bilateral radiographic infiltrates (1). Although the prevalence of ARDS is expected to increase worldwide, there is no effective treatment for this fatal disease. Corticosteroids have been the most widely studied drugs for ARDS and are the only agents that have shown promise as a potential treatment. In the present study, the increased sample size allowed the detection of a significant treatment effect in terms of mortality reduction. As a result, a lower mortality rate was identified in the low-dose group compared with the control group, with a combined OR of 0.43 and a $95 \%$ CI of 0.24-0.79. Furthermore, there was a significantly lower mortality in patients who were administered with steroids early compared with the controls (OR: 0.46; 95\% CI: 0.21-1.01), but not when comparing patients with late administrations of corticosteroids with the controls. The beneficial effects of corticosteroid therapy observed in the present analysis concurred with previous trials, which showed improved $\mathrm{PaO}_{2} / \mathrm{FiO}_{2}$ ratios and reduced periods of mechanical ventilation in ARDS in response to treatment with low doses of methylprednisolone (10-12). Furthermore, the pooled estimates, provided by the random effects model, considered the heterogeneity evident across existing studies.

Over recent decades, the dosage and timing of corticosteroid therapy for patients with ARDS has changed. Prior to 1990 , previous studies usually used a high daily dose $(30 \mathrm{mg} / \mathrm{kg}$ ) over a short period of time ( $\leq 2$ days) in order to prevent or treat ARDS. Some investigators suggested different treatment doses for early ARDS and persistent ARDS in which a duration of ARDS $\leq 3$ days was considered as early ARDS and $\geq 5$ days as persistent or non-resolving ARDS $(31,32)$. In addition, sub-group analysis of the ARDS net steroid study recommended against starting corticosteroid therapy $>14$ days after the onset of ARDS (25). These findings suggested that a particular sub-group of patients with ARDS might benefit the most from corticosteroid therapy: Those with persistent ARDS and an onset of ARDS <14 days.

The results in a number of previous studies $(10-12,24,25)$ have demonstrated that treatments with low doses of corticosteroids have been associated with a lower mortality rate for 
patients with ARDS. In 2006, a previous study conducted by Annane et al (10) demonstrated that a 7 day treatment, involving low doses of corticosteroids, was associated with better outcomes in septic shock-associated early ARDS non-responders, but not in responders. In this previous study, patients underwent a short corticotropin test with $250 \mathrm{mg}$ tetracosactrin (Synacthène Ciba), which was administered intravenously before randomization. Patients were then graded as responders when cortisol increased by $<9 \mathrm{~g} / \mathrm{dl}$ $(250 \mathrm{nmol} / \mathrm{l})(10)$. The effect on mortality was consistent in both randomized and non-randomized studies (cohort studies), and highlighted the need for multiple-center, placebo-controlled, randomized and double-blind trials to confirm efficacy. In 2014, a previous study conducted by Ruan et al (33) showed that the effects of corticosteroids on the mortality of patients with ARDS differed by way of the duration of outcome measures and by etiologies. Corticosteroids did not improve longer-term outcomes and may have caused harm in certain sub-groups. However, the number of RCTs and sample size were relatively small. There were only two studies in some sub-group analyses and the statistical power was insufficient in some cases. In the present study, different sub-groups were analyzed and only RCT studies were selected, resulting in a more scientifically rigorous conclusion.

Due to the limitations of the present data, it was only possible to conduct a pooled analysis of mortality in relation to incident infection, and the number of days alive and off mechanical ventilation. Therefore, the effects of glucocorticoids on ARDS was not investigated thoroughly. Compared with other meta-analyses, the effect of prolonged glucocorticoid treatment was not assessed, as outcome data from pooled studies were used. The present study was also limited by the inclusion of small to moderately sized RCTs with a relatively small number of events and the satisfied and RCT designs were included to solve the problem of corticoids in patients with ARDS, resulting in the inclusion of two old studies. Furthermore, it was not possible to completely rule out publication bias.

The present meta-analysis suggested that corticosteroid treatment can reduce the mortality rate of patients with ARDS, particularly in the early stages. Glucocorticoid treatment can alleviate systemic inflammation and accelerate the resolution of ARDS. However, high-dose glucocorticoid treatment and the late administration of glucocorticoids did not significantly improve the outcome of patients with ARDS. This result suggested that the duration of glucocorticoid therapy is just as important, in terms of treatment effects, as the dose itself. The present results also suggested that the number of days the patients remained alive, and the number of days for on/off mechanical ventilation, as well as the $\mathrm{PaO}_{2} / \mathrm{FiO}_{2}$ ratio, improved following the administration of glucocorticoid. The use of steroids was not associated with the risk of new infection in patients with ARDS undergoing steroid treatment. Therefore, the present analyses demonstrated that corticosteroid therapy is associated with a trend towards reduced mortality rates.

\section{Acknowledgements}

Not applicable.

\section{Funding}

The present study was supported by Jiangsu Provincial Key Research and Development Program (grant no. BE2016721), Natural science Foundation of Jiangsu Province (grant no. BK20191351) and Jiangsu Planned Projects for Postdoctoral Research Funds (grant no. 2019k178).

\section{Availability of data and materials}

The datasets used and/or analyzed during the current study are available from the corresponding author on reasonable request.

\section{Authors' contributions}

BW and DDL conceptualized and designed this study. SSS provided the study materials. DDL, HZ and XWZ collected and assembled the data. SSS and XWZ analyzed and interpreted the data. All authors wrote the manuscript and approved the final version of the manuscript.

\section{Ethics approval and consent to participate}

Not applicable.

\section{Patient consent for publication}

Not applicable.

\section{Competing interests}

The authors declare that they have no competing interests.

\section{References}

1. Ware LB and Matthay MA: The acute respiratory distress syndrome. N Engl J Med 342: 1334-1349, 2000.

2. Meduri GU, Annane D, Chrousos GP, Marik PE and Sinclair SE: Activation and regulation of systemic inflammation in ARDS: Rationale for prolonged glucocorticoid therapy. Chest 136: 1631-1643, 2009

3. Meduri GU and Eltorky MA: Understanding ARDS-associated fibroproliferation. Intensive Care Med 41: 517-520, 2015.

4. Roch A, Guervilly C and Papazian L: Fluid management in acute lung injury and ards. Ann Intensive Care 1: 16, 2011.

5. Lamberts SW, Bruining HA and de Jong FH: Corticosteroid therapy in severe illness. N Engl J Med 337: 1285-1292, 1997.

6. Chirousos GP: The hypothalamic-pituitary-adrenal axis and immune-mediated inflammation. N Engl J Med 332: 1351-1362, 1995.

7. Udelsman R, Ramp J, Gallucci WT, Gordon A, Lipford E, Norton JA, Loriaux DL and Chrousos GP: Adaptation during surgical stress. A reevaluation of the role of glucocorticoids. J Clin Invest 77: 1377-1381, 1986.

8. MacLaren R and Jung R: Stress-dose corticosteroid therapy for sepsis and acute lung injury or acute respiratory distress syndrome in critically ill patients. Pharmacotherapy 22: 1140-1156, 2002.

9. Newton R: Molecular mechanisms of glucocorticoid action: What is important? Thorax 55: 603-613, 2000.

10. Annane D, Sébille V and Bellissant E; Ger-Inf-05 Study Group: Effect of low doses of corticosteroids in septic shock patients with or without early acute respiratory distress syndrome. Crit Care Med 34: 22-30, 2006.

11. Confalonieri M, Urbino R, Potena A, Piattella M, Parigi P, Puccio G, Della Porta R, Giorgio C, Blasi F, Umberger R and Meduri GU: Hydrocortisone infusion for severe community-acquired pneumonia: A preliminary randomized study. Am J Respir Crit Care Med 171: 242-248, 2005. 
12. Meduri GU, Golden E, Freire AX, Taylor E, Zaman M, Carson SJ, Gibson $M$ and Umberger R: Methylprednisolone infusion in early severe ARDS: Results of a randomized controlled trial. Chest 131: 954-963, 2007.

13. Foster JR, Steroids for early acute respiratory distress syndrome: Critical appraisal of Meduri GU, Golden E, Freire AX, et al: Methylprednisolone infusion in early severe ARDS: Results of a randomized controlled trial. Chest 2007; 131: 954-963. Pediatr Crit Care Med 11: 404-407, 2010.

14. Lamontagne F, Briel M, Guyatt GH, Cook DJ, Bhatnagar N and Meade M: Corticosteroid therapy for acute lung injury, acute respiratory distress syndrome and severe pneumonia: A meta-analysis of randomized controlled trials. J Crit Care 25 420-435, 2010.

15. Hoogwerf B and Danese RD: Drug selection and the management of corticosteroid-related diabetes mellitus. Rheum Dis Clin North Am 25: 489-505, 1999.

16. McDonough AK, Curtis JR and Saag KG: The epidemiology of glucocorticoid-associated adverse events. Curr Opin Rheumatol 20: 131-137, 2008.

17. Weigelt JA, Norcross JF, Borman KR and Snyder WH III: Early steroid therapy for respiratory failure. Arch Surg 120: 536-540, 1985.

18. Agarwal R, Nath A, Aggarwal A and Gupta D: Do glucocorticoids decrease mortality in acute respiratory distress syndrome? A meta-analysis. Respirology 12: 585-590, 2007.

19. Ranieri VM, Rubenfeld GD, Thompson BT, Ferguson ND, Caldwell E, Fan E, Camporota L and Slutsky AS: Acute respiratory distress syndrome: The berlin definition. JAMA 307 2526-2533, 2012.

20. Savović J, Weeks L, Sterne JA, Turner L Altman DG, Moher D and Higgins JP: Evaluation of the Cochrane Collaboration's tool for assessing the risk of bias in randomized trials: Focus groups, online survey, proposed recommendations and their implementation. Syst Rev 3: 37, 2014

21. Zeiss EE and Hanley JA: Mantel-Haenszel techniques and logistic regression: Always examine one's data first and don't overlook the simpler techniques. Paediatr Perinat Epidemiol 6 : 311-315, 1992

22. Higgins JP and Green S (eds): Cochrane handbook for systematic reviews of interventions. Version 5.2.0. The Cochrane Collaboration, 2017.

23. Ning G, et al: The guidelines for clinical usage of glucocorticoid. Chin J Endocrinol Metab 28, 2012.

24. Lee HS, Lee JM, Kim MS, Kim HY, Hwangbo B and Zo JI: Low-dose steroid therapy at an early phase of postoperative acute respiratory distress syndrome. Ann Thorac Surg 79: 405-410, 2005.
25. Liu L, Li J, Huang YZ, Liu SQ, Yang CS, Guo FM, Qiu HB and Yang Y: The effect of stress dose glucocorticoid on patients with acute respiratory distress syndrome combined with critical illness-related corticosteroid insufficiency. Zhonghua Nei Ke Za Zhi 51: 599-603, 2012 (In Chinese).

26. Seam N, Meduri GU, Wang H, Nylen ES, Sun J, Schultz MJ, Tropea M and Suffredini AF: Effects of methylprednisolone infusion on markers of inflammation, coagulation, and angiogenesis in early acute respiratory distress syndrome. Crit Care Med 40: 495-501, 2012.

27. Steinberg KP, Hudson LD, Goodman RB, Hough CL, Lanken PN, Hyzy R, Thompson BT and Ancukiewicz M: National heart, lung, and blood institute acute respiratory distress syndrome(ARDS) clinical trials network: Efficacy and safety of corticosteroids for persistent acute respiratory distress syndrome. N Engl J Med 354: 1671-1684, 2006.

28. Wan MH, Li J, Gong HL, Xue P, Zhu L, Chen GY, Xia Q and Wen-Fu T: Clinical observation on the effect of dexamethasone and Chinese herbal decoction for purgation in severe acute pancreatitis patients. Chin J Integr Med 17: 141-145, 2011.

29. Bernard GR, Luce JM, Sprung CL, Rinaldo JE, Tate RM, Sibbald WJ, Kariman K, Higgins S, Bradley R and Metz CA: High-dose corticosteroids in patients with the adult respiratory distress syndrome. N Engl J Med 317: 1565-1570, 1987.

30. Thompson BT: Glucocorticoids and acute lung injury. Crit Care Med 31 (4 Suppl): S253-S257, 2003.

31. Bone RC, Fisher CJ, Clemmer TP, Slotman GJ, Metz CA and Balk RA: Sepsis syndrome: A valid clinical entity. Methylprednisolone severe sepsis study group. Crit Care Med 17: 389-393, 1989.

32. Luce JM, Montgomery AB, Marks JD, Turner J, Metz CA and Murray JF: Ineffectiveness of high-dose methylprednisolone in preventing parenchymal lung injury and improving mortality in patients with septic shock. Am Rev Respir Dis 138: 62-68, 1988.

33. Ruan SY, Lin HH, Huang CT, Kuo PH, Wu HD and Yu CJ Exploring the heterogeneity of effects of corticosteroids on acute respiratory distress syndrome: A systematic review and meta-analysis. Crit Care 18: R63, 2014.

This work is licensed under a Creative Commons Attribution-NonCommercial-NoDerivatives 4.0 International (CC BY-NC-ND 4.0) License. 